\title{
Familial Hypercholesterolemia in Patients with Acute Coronary Syndrome: Genetic Insights from EXPLORE-J
}

\author{
Mariko Harada-Shiba ${ }^{1}$, Junya Ako $^{2}$, Atsushi Hirayama ${ }^{3}$, Masato Nakamura $^{4}$, Atsushi Nohara ${ }^{5}$, Kayoko Sato ${ }^{6}$, \\ Yoshitaka Murakami ${ }^{7}$, Ryusuke Koshida ${ }^{8}$, Asuka Ozaki ${ }^{8}$ and Hidenori Arai ${ }^{9}$
}

\author{
${ }^{1}$ Department of Molecular Pathogenesis, National Cerebral and Cardiovascular Center Research Institute, Osaka, Japan \\ ${ }^{2}$ Department of Cardiovascular Medicine, Kitasato University, Kanagawa, Japan \\ ${ }^{3}$ Cardiovascular Division, Osaka Police Hospital, Osaka, Japan \\ ${ }^{4}$ Division of Cardiovascular Medicine, Toho University Ohashi Medical Center, Tokyo, Japan \\ ${ }^{5}$ Department of Clinical Genetics, Ishikawa Prefectural Central Hospital, Kanazawa, Japan \\ ${ }^{6}$ Department of Cardiology, Tokyo Women's Medical University, Tokyo, Japan \\ ${ }^{7}$ Department of Medical Statistics, Toho University, Tokyo, Japan \\ ${ }^{8}$ Sanofi K.K., Tokyo, Japan \\ ${ }^{9}$ National Center for Geriatrics and Gerontology, Aichi, Japan
}

Aim: Genetic testing can provide a definitive diagnosis of familial hypercholesterolemia (FH). However, accessibility of genetic testing may be limited in certain countries where it is not considered "standard of care," including Japan. In addition, mutations responsible for $\mathrm{FH}$ cannot be identified in approximately $30 \%$ of patients.

Methods: EXPLORE-J is a multicenter, prospective, observational study of patients presenting with acute coronary syndrome (ACS). The genetic data were analyzed and adjudicated as pathogenic, indeterminate, or nondetectable pathogenic variant.

Results: Of 1,944 patients, 431 underwent genetic screening. Overall, most patients had nonpathogenic variants of $L D L R, L D L R A P 1$, or PCSK9 ( $n=396,91.9 \%)$. Of the $25(5.8 \%)$ patients with pathogenic variants, variants of the $L D L R$ gene and the PCSK9 gene were seen in 10 and 15 patients, respectively. Indeterminate variants were observed in $10(2.3 \%)$ patients. Of the 431 patients, eight $(1.9 \%)$ met the criteria for a diagnosis of FH using the Japanese Atherosclerosis Society (JAS) 2017 guidelines. When genetic data were incorporated, $33(7.7 \%)$ patients met the JAS guidelines. No patients with FH pathogenic variants satisfied the JAS clinical criteria for a diagnosis of $\mathrm{FH}$.

Conclusions: The results revealed a higher prevalence of genetic mutations of FH among Japanese patients with ACS and a low sensitivity of the FH diagnostic criteria of the JAS 2017 guidelines. These findings highlight the difficulties of FH diagnosis in patients with ACS in the acute phase and suggest the importance of genetic testing and family history.

Key words: Familial hypercholesterolemia, Genetic testing, Japan, Acute coronary syndrome

\section{Introduction}

Familial hypercholesterolemia $(\mathrm{FH})$ is an inherited autosomal dominant disease that is characterized by severely elevated low-density lipoprotein cholesterol (LDL-C), early-onset coronary artery disease (CAD), and tendon or cutaneous xanthomas ${ }^{1-3)}$. The prevalence of $\mathrm{FH}$ worldwide is approximately 1 in 200-500, and the estimated number of cases of FH in Japan is 300,000 ${ }^{4)}$. However,

Address for correspondence: Mariko Harada-Shiba, Department of Molecular Pathogenesis, National Cerebral and Cardiovascular Center Research Institute, 6-1 Kishibe-shinmachi, Suita, Osaka 564-8565, Japan E-mail: mshiba@ncvc.go.jp

Received: May 10, $2021 \quad$ Accepted for publication: August 1, 2021

Copyright@2021 Japan Atherosclerosis Society

This article is distributed under the terms of the latest version of CC BY-NC-SA defined by the Creative Commons Attribution License. 
in Japan, less than 1\% of those with FH are estimated to have been diagnosed using the Dutch Lipid Clinical Network guidelines ${ }^{5)}$.

The diagnosis of FH may include a combination of family history, clinical signs (e.g., tendon xanthomas), and LDL-C levels. Although there are several guidelines for the clinical diagnosis of $\mathrm{FH}$, including the Japan Atherosclerosis Society (JAS) 2017 guidelines ${ }^{6}$, the Dutch Lipid Clinical Network guidelines5), and the Simon Broome Register guidelines ${ }^{7)}$, there are differences between these guidelines in the criteria used to diagnose $\mathrm{FH}$. The Dutch Lipid Clinical Network and Simon Broome Register guidelines include genetic testing, whereas the JAS 2017 guidelines currently do not.

Genetic testing can provide a definite diagnosis of $\mathrm{FH}$ by detection of pathogenic mutations in the genes coding for the low-density lipoprotein receptor (LDLR), apolipoprotein $\mathrm{B}(\mathrm{apoB})$, and proprotein convertase subtilisin/kexin type 9 (PCSK9) ${ }^{8-10)}$, or a rare recessive form of $\mathrm{FH}$, autosomal recessive hypercholesterolemia, which is caused by loss-offunction mutations in the LDLR adaptor protein-1 (LDLRAP1 $^{8,11)}$. However, accessibility of genetic testing may be limited in countries where it is not considered "standard of care," including Japan ${ }^{12)}$, and in up to $30 \%$ of cases a mutation cannot be identified $^{13)}$.

EXPLORE-J is a prospective, large-scale, observational study using data from an acute coronary syndrome (ACS) registry, conducted at 59 centers in Japan ${ }^{14)}$. ACS encompasses a range of conditions compatible with acute myocardial ischemia and/or myocardial infarction (MI), including ST-segment elevation MI, non-ST-segment elevation MI, and unstable angina ${ }^{15)}$. Large observational studies in Europe have investigated the prevalence of $\mathrm{FH}$ in patients with ACS, including genetically confirmed cases ${ }^{16,17)}$. However, the evidence base for Japan is lacking, and the JAS 2017 guidelines have higher cutoff values for LDL-C and Achilles tendon thickness (ATT) when identifying possible $\mathrm{FH}^{3,14}$. To date, results from the EXPLORE-J study have highlighted the prevalence of FH in patients with ACS in Japan ${ }^{18)}$, as well as described lipid management at the time of ACS ${ }^{19)}$. Using the JAS 2017 guidelines, $\mathrm{FH}$ was approximately five times more prevalent in patients with ACS than in the general population ${ }^{18)}$.

\section{Aim}

The overall aim of EXPLORE-J was to evaluate lipid management and persistent cardiovascular risk in patients hospitalized for ACS, with a focus on underlying hypercholesterolemia and $\mathrm{FH}^{14)}$. The current analysis of the EXPLORE-J registry aimed to identify the characteristics of patients with confirmed pathogenic variants associated with $\mathrm{FH}$. In addition, this analysis aimed to evaluate $\mathrm{FH}$ prevalence in patients with ACS, both with and without genetic testing, according to the JAS 2017 guidelines, the Dutch Lipid Clinical Network guidelines, and the Simon Broome Register guidelines.

\section{Methods}

\section{Study Design and Patients}

EXPLORE-J was a multicenter, prospective, observational study that was conducted between April 2015 and August 2018. Full details of the methods have been published previously ${ }^{14}$. In brief, patients with ACS who required hospitalization were recruited and registered at 59 sites between April 2015 and August 2016. Patients were then followed up for 2 years. Baseline data, including LDL-C levels, presence of xanthoma, and family history, were reported at Visit 1, within 14 days after hospitalization due to ACS.

\section{Genetic Examinations}

Separate informed consent was obtained for genetic examinations. Single nucleotide variations or insertion/deletion in genes encoding key proteins were evaluated. Mutations in genes encoding key proteins involved in the LDLR endocytic and recycling pathways were analyzed (LDLR; LDLRAP1; PCSK9). The $A P O B$ gene was not analyzed because no cases of $A P O B$ mutations had been previously reported in the Japanese population when the analysis was conducted $^{6)}$. Genetic mutations were categorized as nonpathogenic variant $(-)$, indeterminate pathogenic variant $( \pm$, not reported previously, but potentially pathogenic), and pathogenic variant $(+$, reported pathogenicity of $\mathrm{FH}$ ). The variants detected in the LDLR or PCSK9 genes were classified as pathogenic using ClinVar, the Leiden Open Variation database, and population data from the Exome Aggregation Consortium, the Japanese Human Genetic Variation Database, and the Tohoku Medical Megabank Organization, as well as in silico tools/software, and functional data based on guidelines edited by the American College of Medical Genetics and Genomics and the Association for Molecular Pathology.

\section{Diagnosis of FH}

In this study, three sets of diagnostic guidelines for $\mathrm{FH}$ were used for each patient: the JAS 2017 guidelines ${ }^{6}$, the Dutch Lipid Clinical Network

\section{Advance Publication Journal of Atherosclerosis and Thrombosis}


Table 1. Diagnostic guidelines for FH

\begin{tabular}{|c|c|}
\hline Diagnostic guidelines & Criteria \\
\hline \multirow{8}{*}{$\begin{array}{l}\text { The Japanese Atherosclerosis } \\
\text { Society guidelines }{ }^{6} \text { ) }\end{array}$} & At least two of the following: \\
\hline & - Hyper LDL-C ( $\geq 180 \mathrm{mg} / \mathrm{dL}$ before treatment) \\
\hline & - Secondary hyperlipidemia is excluded \\
\hline & - Lipid levels before treatment are considered if patients were on medications \\
\hline & - FH is strongly suspected if LDL-C is $\geq 250 \mathrm{mg} / \mathrm{dL}$ \\
\hline & $\begin{array}{l}\text { - Tendon xanthoma (tendon xanthoma in the back of hand, elbow, knee, etc.; or Achilles tendon } \\
\text { thickening } \geq 9 \mathrm{~mm} \text { ) or tuberous xanthoma (excluding xanthelasma of eyelid) }\end{array}$ \\
\hline & $\begin{array}{l}\text { - Familial history of FH (blood relatives within the second degree of kinship) or early-onset CAD (male } \\
\text { subjects aged }<55 \text { years; female subjects aged }<65 \text { years) }\end{array}$ \\
\hline & Diagnosis by genetic testing is advised if $\mathrm{FH}$ is suspected \\
\hline \multirow[t]{5}{*}{$\begin{array}{l}\text { The Dutch Lipid Clinical } \\
\text { Network guidelines for } \mathrm{FH}^{\text {a } 5}\end{array}$} & $\begin{array}{l}\text { Family history: First-degree relative with known premature coronary and vascular disease ( } 1 \text { point); first- } \\
\text { degree relative with known LDL-C level above the } 95 \text { th percentile }{ }^{b}(1 \text { point); first-degree relative with } \\
\text { tendon xanthoma and/or corneal arcus }{ }^{b}(2 \text { points); children aged }<18 \text { years with LDL-C level above the } \\
\text { 95th percentile }{ }^{b} \text { ( } 2 \text { points) }\end{array}$ \\
\hline & $\begin{array}{l}\text { Clinical history: Patient with premature cerebral or peripheral vascular disease ( } 1 \text { point); or patient with } \\
\text { premature CAD ( } 2 \text { points) }\end{array}$ \\
\hline & Physical examination: Corneal arcus prior to age 45 years ${ }^{b}$ ( 4 points); or tendinous xanthoma ( 6 points) \\
\hline & Genetic testing: Functional mutation in the $L D L R, A P O B^{\mathrm{b}}$, or $P C S K 9$ genes (8 points) \\
\hline & $\begin{array}{l}\text { LDL-C levels: } 155-189 \mathrm{mg} / \mathrm{dL} \text { ( } 1 \text { point) } ; 190-249 \mathrm{mg} / \mathrm{dL} \text { ( } 3 \text { points); } 250-329 \mathrm{mg} / \mathrm{dL} \text { ( } 5 \text { points); } \geq 330 \\
\mathrm{mg} / \mathrm{dL} \text { (8 points) }\end{array}$ \\
\hline \multirow[t]{5}{*}{$\begin{array}{l}\text { The Simon Broome } \\
\text { guidelines }\end{array}$} & $\begin{array}{l}\text { Criterion 1: Total cholesterol levels }>290 \mathrm{mg} / \mathrm{dL} \text { or LDL-C }>190 \mathrm{mg} / \mathrm{dL} \text { in adults; or total cholesterol } \\
\text { levels }>260 \mathrm{mg} / \mathrm{dL} \text { or LDL-C }>155 \mathrm{mg} / \mathrm{dL} \text { in children }{ }^{2}\end{array}$ \\
\hline & Criterion 2: Tendon xanthomas in the patient, or tendon xanthomas in a first- or second-degree relative ${ }^{b}$ \\
\hline & $\begin{array}{l}\text { Criterion 3: DNA-based evidence of an } L D L R \text { mutation, familial defective apoB- } 100^{\mathrm{b}} \text {, or a } P C S K 9 \\
\text { mutation }\end{array}$ \\
\hline & $\begin{array}{l}\text { Criterion 4: Family history of myocardial infarction in a second-degree relative }<50 \text { years of age or first- } \\
\text { degree relative }<60 \text { years of age }\end{array}$ \\
\hline & $\begin{array}{l}\text { Criterion 5: Family history of elevated total cholesterol }>290 \mathrm{mg} / \mathrm{dL} \text { in an adult first- or second-degree } \\
\text { relative; or family history of elevated total cholesterol }>260 \mathrm{mg} / \mathrm{dL} \text { in a child, brother, or sister aged } \leq 16 \\
\text { years }\end{array}$ \\
\hline
\end{tabular}

ApoB, apolipoprotein B; CAD, coronary artery disease; FH, familial hypercholesterolemia; LDL-C, low-density lipoprotein cholesterol; LDLR, low-density lipoprotein receptor; PCSK9, proprotein convertase subtilisin/kexin type 9.

a -5 points indicate possible $\mathrm{FH}, 6-8$ points indicate probable $\mathrm{FH}$, and $>8$ points indicate definite $\mathrm{FH}$.

${ }^{\mathrm{b}}$ Criteria not collected as part of the EXPLORE-J study.

${ }^{\mathrm{c}}$ Criterion $1+2$ or 3 indicated definitive $\mathrm{FH}$; criterion $1+4$ or 5 indicated possible $\mathrm{FH}$.

guidelines ${ }^{5)}$, and the Simon Broome guidelines ${ }^{7)}$. Details of each are shown in Table 1. Diagnoses of FH by the JAS 2017 guidelines were conducted both with and without genetic testing as a definitive criterion (identification of a pathogenic variant led to a positive $\mathrm{FH}$ diagnosis; functional variants in $L D L R$ and PCSK9 genes were screened in EXPLORE-J).

The following criteria were assessed as they are included in all three guidelines for the diagnosis of FH: LDL-C, ATT, and family history of CAD. The highest available measurement of LDL-C obtained at or before Visit 1 was used for the diagnosis of $\mathrm{FH}$. LDL-C was also measured (calculated or direct) prior to hospitalization without treatment (for patients who had available LDL-C values off statin treatment any time before hospitalization) and after hospitalization.
In this study, both calculated (e.g., by the Friedewald equation) and/or direct (e.g., by homogeneous direct methods) LDL-C values were collected. For these analyses, calculated LDL-C values were used if available; if calculated LDL-C values were not available, direct LDL-C values were used. ATT was measured at the central reading laboratory by blinded investigators. In addition, family history of CAD was collected at enrollment to help facilitate $\mathrm{FH}$ diagnosis.

\section{Statistical Analyses}

Baseline characteristics and LDL-C values between genetic variants were described by mean, median, standard deviation, and range for continuous data, and by proportion in each category for categorical data. For comparisons of baseline

\section{Advance Publication Journal of Atherosclerosis and Thrombosis}


Table 2. Baseline characteristics by genetic variants ${ }^{18)}$

\begin{tabular}{|c|c|c|c|c|c|}
\hline & $\begin{array}{c}\text { Nonpathogenic } \\
\text { variant }(-)(n=396)\end{array}$ & $\begin{array}{l}\text { Indeterminate variant } \\
\qquad( \pm)(n=10)\end{array}$ & $\begin{array}{l}\text { Pathogenic variant } \\
\qquad(+)(n=25)\end{array}$ & $\begin{array}{c}\text { Total } \\
(n=431)\end{array}$ & $P$-value \\
\hline Age, years, mean (SD) & $65.7(11.7)$ & $69.7(12.2)$ & $63.6(10.8)$ & $65.7(11.7)$ & 0.378 \\
\hline Male, $n(\%)$ & $317(80.1)$ & $7(70.0)$ & $19(76.0)$ & $343(79.6)$ & 0.528 \\
\hline Female, $n(\%)$ & $79(19.9)$ & $3(30.0)$ & $6(24.0)$ & $88(20.4)$ & \\
\hline BMI, $\mathrm{kg} / \mathrm{m}^{2}$, mean $(\mathrm{SD})$ & $24.3(3.8)^{\mathrm{a}}$ & $24.1(3.3)$ & $23.0(3.3)$ & $24.3(3.8)^{b}$ & 0.221 \\
\hline Weight, kg, mean (SD) & $65.5(13.4)^{\mathrm{a}}$ & $64.0(15.9)$ & $62.9(12.7)$ & $65.3(13.4)^{b}$ & 0.633 \\
\hline STEMI, $n(\%)$ & $270(68.2)$ & $7(70.0)$ & $18(72.0)$ & $295(68.4)$ & 0.732 \\
\hline NSTEMI, $n(\%)$ & $52(13.1)$ & $1(10.0)$ & $1(4.0)$ & $54(12.5)$ & \\
\hline Unstable angina, $n(\%)$ & $74(18.7)$ & $2(20.0)$ & $6(24.0)$ & $82(19.0)$ & \\
\hline Diabetes mellitus, $n(\%)$ & $144(36.4)$ & $3(30.0)$ & $6(24.0)$ & $153(35.5)$ & 0.446 \\
\hline Hypertension, $n(\%)$ & $305(77.0)$ & $10(100.0)$ & $17(68.0)$ & $332(77.0)$ & 0.123 \\
\hline Dyslipidemia, $n(\%)$ & $306(77.3)$ & $9(90.0)$ & $23(92.0)$ & $338(78.4)$ & 0.152 \\
\hline \multicolumn{6}{|c|}{ Therapy before hospitalization, $n(\%)$} \\
\hline Statin & $97(24.5)$ & $1(10.0)$ & $10(40.0)$ & $108(25.1)$ & 0.133 \\
\hline Intensive statin $^{c}$ & $16(4.0)$ & $0(0.0)$ & $0(0.0)$ & $16(3.7)$ & 0.449 \\
\hline Ezetimibe & $4(1.0)$ & $0(0.0)$ & $1(4.0)$ & $5(1.2)$ & 0.347 \\
\hline Statin + ezetimibe & $0(0.0)$ & $0(0.0)$ & $1(4.0)$ & $1(0.2)$ & - \\
\hline
\end{tabular}

BMI, body mass index; NSTEMI, non-ST-elevation myocardial infarction; SD, standard deviation; STEMI, ST-elevation myocardial infarction. Baseline characteristics were collected at Visit 1.

${ }^{\mathrm{a}} n=395 .{ }^{\mathrm{b}} n=430 .{ }^{\mathrm{c}}$ Atorvastatin $\geq 20 \mathrm{mg}$, rosuvastatin $\geq 10 \mathrm{mg}$, and pitavastatin $\geq 4 \mathrm{mg}$.

characteristics and LDL-C values, $P$-values are provided for baseline characteristics based on Fisher's exact test for categorical variables and analysis of variance tests for continuous variables. A two-sided $P$-value of $<0.05$ was considered significant. Comparisons between diagnostic guidelines for genetic variants are descriptive only. Receiver operating characteristic (ROC) curves were plotted for LDL-C and ATT to FH diagnosis, and cut-off values were obtained using the Youden index ${ }^{20)}$.

\section{Ethics Approval and Consent to Participate}

This study was conducted in compliance with the Declaration of Helsinki (amended in October 2013) and the Ethical Guidelines for Medical and Health Research Involving Human Subjects (enacted on December 22, 2014). Prior to the study initiation, the investigator or sub-investigators submitted the protocol and informed consent form to the ethical review committee of each study center and obtained their approval. Patient anonymity was protected by the use of subject identification codes. A co-operation fee of 5000 Japanese yen (approximately US $\$ 42$ or $€ 37$ in October 2015) for study participation was provided for each patient on request from the study center. All patients were required to provide written informed consent.

\section{Results}

In total, 1,944 patients were included in the EXPLORE-J study. Of these, 431 underwent genetic testing and were analyzed. Pathogenic variants were observed in $25(5.8 \%)$ patients. Of these 25 patients, $10(40.0 \%)$ had a pathogenic variant of $L D L R$, and $15(60.0 \%)$ had a pathogenic variant of PCSK9 (Supplementary Table 1). No patients had pathogenic variants of LDLRAP1. Indeterminate variants were observed in $10(2.3 \%)$ patients (Supplementary Table 2). Of these, five (50.0\%) patients had indeterminate variants of $L D L R$ and another five $(50.0 \%)$ had indeterminate variants of PCSK9. Overall, most patients had nonpathogenic variants of LDLR, LDLRAP1, or PCSK9 $(n=396$, 91.9\%).

Baseline characteristics are shown in Table 2. Overall, the baseline characteristics of the 431 patients who underwent genetic testing were similar to those previously reported for the entire EXPLORE-J population (mean [standard deviation (SD)] age, 66.0 [12.2] years; men, 80.3\%; mean [SD] body mass index, $24.2[3.6] \mathrm{kg} / \mathrm{m}^{2}{ }^{18)}$. Patients with pathogenic variants had generally higher LDL-C levels at baseline compared with patients with nonpathogenic or indeterminate variants before hospitalization (without medication) and after hospitalization (Table 3). Other baseline characteristics were similar between the 
Table 3. LDL-C levels by genetic variants

\begin{tabular}{|c|c|c|c|c|c|}
\hline LDL-C levels, mg/dL, mean (SD) & $\begin{array}{c}\text { Nonpathogenic } \\
\text { variant }(-)(n=396)\end{array}$ & $\begin{array}{l}\text { Indeterminate variant } \\
\qquad( \pm)(n=10)\end{array}$ & $\begin{array}{l}\text { Pathogenic variant } \\
\qquad(+)(n=25)\end{array}$ & $\begin{array}{c}\text { Total } \\
(n=431)\end{array}$ & $P$-value \\
\hline$n$ & 392 & 10 & 25 & 427 & \\
\hline Maximum value at baseline & $125.1(41.0)$ & $135.5(33.2)$ & $157.2(57.3)$ & $127.2(42.5)$ & $<0.001$ \\
\hline$n$ & 88 & 5 & 3 & 96 & \\
\hline $\begin{array}{l}\text { Measurement without medication before } \\
\text { hospitalization }\end{array}$ & $131.5(37.4)$ & $137.4(41.3)$ & $179.7(99.2)$ & $133.3(40.4)$ & 0.123 \\
\hline$n$ & 374 & 10 & 24 & 408 & \\
\hline First measurement after hospitalization & $119.4(40.4)$ & $126.9(38.0)$ & $148.1(51.9)$ & $121.2(41.6)$ & 0.004 \\
\hline$n$ & 346 & 10 & 24 & 380 & \\
\hline Direct method & $93.3(31.1)$ & $107.7(27.7)$ & $130.9(51.1)$ & $96.1(33.8)$ & $<0.001$ \\
\hline$n$ & 343 & 10 & 24 & 377 & \\
\hline Calculated & $91.9(31.3)$ & $106.6(27.4)$ & $124.3(38.9)$ & $94.4(32.7)$ & $<0.001$ \\
\hline
\end{tabular}

LDL-C, low-density lipoprotein cholesterol; SD, standard deviation.

Table 4. The percentage of patients meeting the JAS guideline criteria by genetic variants

\begin{tabular}{|c|c|c|c|c|}
\hline \multicolumn{2}{|l|}{ JAS guideline criteria } & \multirow{2}{*}{$\begin{array}{l}\text { All patients }(n=431) \\
325(75.4)\end{array}$} & \multirow{2}{*}{$\begin{array}{l}\text { Nonpathogenic variants } \\
(-) \text { and indeterminate } \\
\text { variants }( \pm)(n=406) \\
308(75.9)\end{array}$} & \multirow{2}{*}{$\begin{array}{l}\text { Pathogenic variants }(+) \\
\qquad(n=25) \\
17(68.0)\end{array}$} \\
\hline Family history of early-onset $\mathrm{CAD}^{\mathrm{a}}$ & No & & & \\
\hline & Yes & $29(6.7)$ & $28(6.9)$ & $1(4.0)$ \\
\hline & Unknown & 77 (17.9) & $70(17.2)$ & $7(28.0)$ \\
\hline \multirow[t]{3}{*}{ ATT } & $<9 \mathrm{~mm}$ & $358(83.1)$ & $337(83.0)$ & $21(84.0)$ \\
\hline & $\geq 9 \mathrm{~mm}$ & $19(4.4)$ & $17(4.2)$ & $2(8.0)$ \\
\hline & Unknown & $54(12.5)$ & $52(12.8)$ & $2(8.0)$ \\
\hline \multirow[t]{3}{*}{ Baseline LDL-C levels (maximum value) } & $<180 \mathrm{mg} / \mathrm{dL}$ & $384(89.1)$ & 385 (89.9) & $19(76.0)$ \\
\hline & $\geq 180 \mathrm{mg} / \mathrm{dL}$ & $43(10.0)$ & $37(9.1)$ & $6(24.0)$ \\
\hline & Unknown & $4(0.9)$ & $4(1.0)$ & $0(0.0)$ \\
\hline
\end{tabular}

${ }^{\text {a }}$ Male $<55$ years, female $<65$ years.

ATT, Achilles tendon thickness; CAD, coronary artery disease; JAS, Japan Atherosclerosis Society; LDL-C, low-density lipoprotein cholesterol.

genetic variants, with no difference observed for any baseline characteristic (Table 2; Table 3).

The percentage of patients meeting each of the three sections (family history of early-onset CAD, ATT, maximum baseline LDL-C levels) of the JAS guidelines by genetic variant is shown in Table 4 . Family history was available for most patients across all genetic variants (overall, 77 [17.9\%] patients had unknown [information unavailable] family history of early-onset CAD).

ATT was available for most patients across all genetic variants (overall, 54 [12.5\%] patients had unknown ATT [ATT unavailable]). Baseline LDL-C was available for most patients (overall, four [0.9\%] patients had unknown baseline LDL-C [baseline LDL-C unavailable]).
Of the patients with known pathogenic variants ( $n=25$; Supplementary Table 1$)$, none of the patients would have been diagnosed with $\mathrm{FH}$ according to the JAS 2017 guidelines. Similarly, of the patients with indeterminate variants $(n=10$; Supplementary Table 2), no patients would have been diagnosed with $\mathrm{FH}$ according to the JAS 2017 guidelines. In addition, two $(8.0 \%)$ patients with pathogenic variants had ATT $\geq 9 \mathrm{~mm}$; however, their highest LDL-C values were 153 and $108 \mathrm{mg} / \mathrm{dL}$, respectively, which did not meet the LDL-C criterion for $\mathrm{FH}$ as per the JAS guidelines.

The percentage of patients meeting criteria for each of the three guidelines for the diagnosis of $\mathrm{FH}$ (the JAS guidelines, the Dutch Lipid Clinical Network guidelines, or the Simon Broome guidelines) is shown

\section{Advance Publication Journal of Atherosclerosis and Thrombosis}



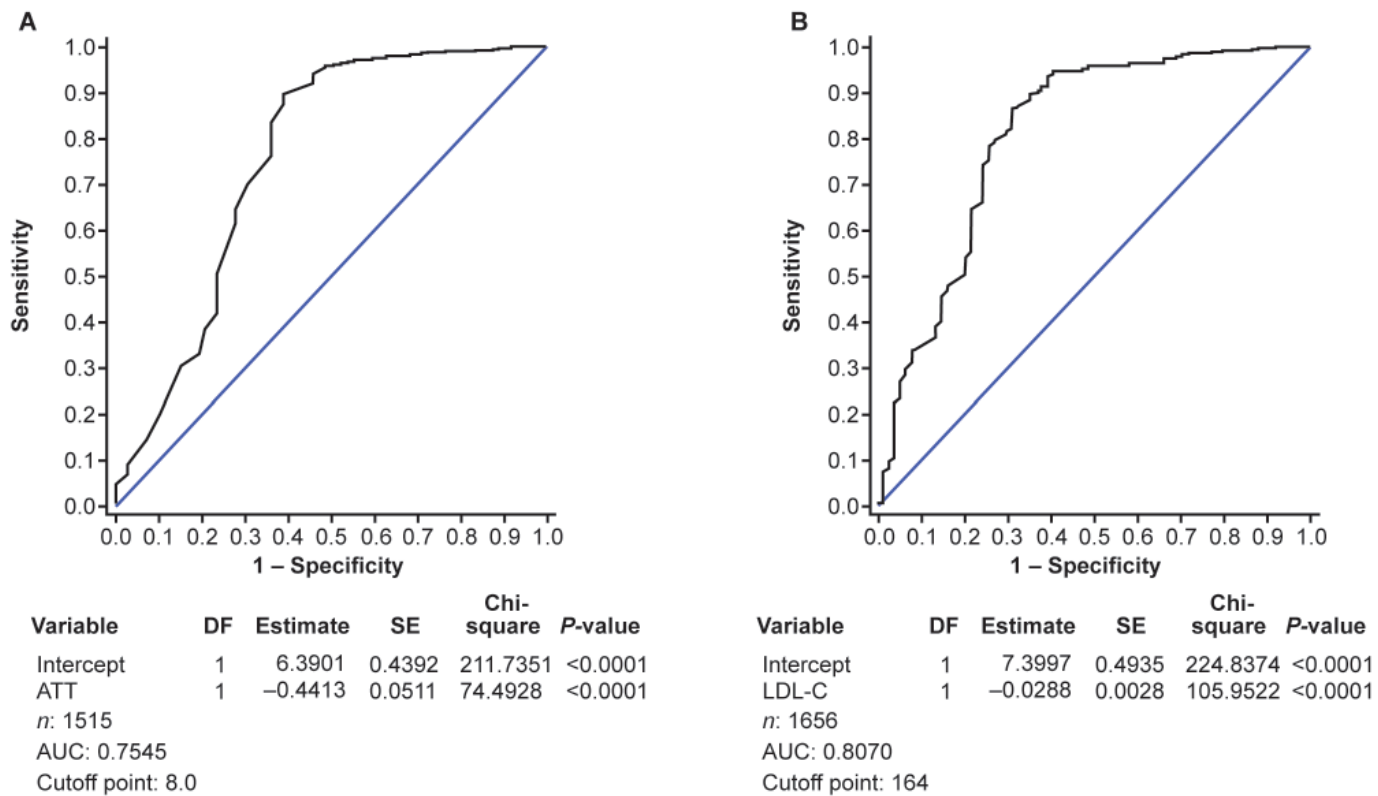

Fig. 1. ROC curve of FH-related parameters on FH judgment via JAS guidelines and FH genetic test for (A) ATT (mm) and (B) LDL-C (max value on/before Visit $1 ; \mathrm{mg} / \mathrm{dL}$ )

ATT, Achilles tendon thickness; AUC, area under the curve; DF, degree of freedom; FH, familial hypercholesterolemia; JAS, Japanese Atherosclerosis Society; LDL-C, low-density lipoprotein cholesterol; ROC, receiver operating characteristic; SE, standard error.

in Supplementary Fig. 1. In total, 398 (92.3\%) patients did not have $\mathrm{FH}$ according to any of the three guidelines. Thirty-three $(7.7 \%)$ patients had definitive $\mathrm{FH}$ according to at least one of the guidelines, and 17 (3.9\%) patients had FH according to both the Dutch Lipid Clinical Network and Simon Broome guidelines. Overall, six (1.4\%) patients had definitive $\mathrm{FH}$ according to all three guidelines.

Without genetic testing, only eight $(1.9 \%)$ of the 431 patients met the JAS 2017 guidelines for $\mathrm{FH}$, compared with definite $\mathrm{FH}$ according to the Dutch Lipid Clinical Network guidelines $(n=6,1.4 \%)$ or the Simon Broome guidelines $(n=6,1.4 \%)$. When the JAS 2017 guidelines were supplemented with genetic data (data not shown), the proportion of patients considered to have $\mathrm{FH}(n=33,7.7 \%)$ was similar to that of definite $\mathrm{FH}$ diagnosed using Dutch Lipid Clinical Network guidelines $(n=17,3.9 \%)$ and the Simon Broome guidelines $(n=31,7.2 \%)$.

ROC curves of parameters of $\mathrm{FH}$ diagnosis via the JAS 2017 guidelines and FH genetic mutations are shown in Fig. 1. Cut-offs of LDL-C $164 \mathrm{mg} / \mathrm{dL}$ and ATT $8.0 \mathrm{~mm}$ have the highest sensitivity and specificity to identify patients with $\mathrm{FH}$ when used as part of the JAS guidelines.

\section{Discussion}

This analysis of a subgroup of patients with ACS from the EXPLORE-J study who underwent FH genetic testing $(n=431)$ provides several major findings: i) overall, $25(5.8 \%)$ patients had pathogenic variants for $\mathrm{FH}$, mostly in PCSK9; ii) no patients with pathogenic variants met the threshold for $\mathrm{FH}$ according to the JAS guidelines; iii) when the JAS guidelines were supplemented with genetic data, the proportion of patients considered to have $\mathrm{FH}$ was similar to that of the Dutch Lipid Clinical Network and Simon Broome guidelines; and iv) when using the JAS guidelines for $\mathrm{FH}$, according to the ROC parameter of values analysis, cut-off values of LDL-C $164 \mathrm{mg} / \mathrm{dL}$ and ATT $8.0 \mathrm{~mm}$ have the highest sensitivity and specificity to identify patients with $\mathrm{FH}$.

Of the 25 patients who had pathogenic variants for $\mathrm{FH}$, many $(n=15,60 \%)$ had a pathogenic variant of PCSK9. There were more mutations in the PCSK9 gene (associated with higher risk of CAD) than previously reported in Japanese patients with pathogenic variants associated with $\mathrm{FH}^{10,21)}$. This may be due to differences in the population, region, and family history of the patient samples in the previous studies. Additionally, the prevalence of the E32K variant of PCSK9 in Japanese patients with pathogenic variants for FH may be higher than that in other countries $^{22-24)}$. Patients who have this mutation show milder phenotypes compared with those with LDLR mutations ${ }^{25}$. Therefore, it may be possible that some Japanese FH patients with this mutation do not meet

\section{Advance Publication Journal of Atherosclerosis and Thrombosis}


the criteria of FH in the JAS 2017 guidelines for this reason and are therefore not diagnosed as having $\mathrm{FH}$.

It is surprising that none of the patients with pathogenic variants would be diagnosed with $\mathrm{FH}$ using the JAS 2017 guidelines. Their LDL-C levels were much lower than those of statin-naïve $\mathrm{FH}$ patients without ACS. One reason for the lack of patients with pathogenic variants meeting the JAS guidelines' definition of $\mathrm{FH}$ could be that $40 \%$ of these patients were receiving a statin. Another reason is that LDL-C levels decrease during the acute phase of ACS. It has been reported that LDL-C can decrease by up to $48 \%$ after acute $\mathrm{MI}^{26}$. These may have masked their untreated LDL-C levels by lowering LDL-C below the $180 \mathrm{mg} / \mathrm{dL}$ threshold required to identify FH with the JAS 2017 guidelines. Cut-off levels of LDL-C for the diagnosis of $\mathrm{FH}$ in the JAS guidelines were determined by using the pre-treatment LDL-C levels in patients with an FH diagnosis and those without ${ }^{27)}$. Furthermore, the JAS guidelines criteria are not designed for patients in the acute phase of ACS.

Notably, four patients with pathogenic variants were reported by their attending physician to have been diagnosed with FH despite not meeting the JAS guidelines for FH during the EXPLORE-J study using ATT. Of these patients, three had LDL-C $<180 \mathrm{mg} /$ $\mathrm{dL}$ and had statin use prior to the index ACS. This further supports the view that signs of FH might be masked in some patients through prior statin use, especially in this population for whom early initiation of high-intensity statin is recommended or who are already on statins at presentation of $\mathrm{ACS}^{6}$.

Statin use can also mitigate the development of xanthoma and reduce ATT ${ }^{28)}$, and some patients may therefore not have had ATT $\geq 9 \mathrm{~mm}$ due to prior statin use. A previous study in Japanese patients with ACS $(n=296)$ demonstrated a prevalence of statin use similar to that in the present study $(23.3 \%$ vs. $25.1 \%$, respectively) ${ }^{29)}$. However, the detection rate of ATT $\geq$ $9 \mathrm{~mm}$ here $(19 / 377 ; 5.0 \%)$ was lower than that reported by Ohmura et al. $(53 / 296 ; 17.9 \%)^{29)}$. Because not all patients with FH have ATT $\geq 9 \mathrm{~mm}$, this may account for differences between these two studies. Patients in the Ohmura et al. study were from residential areas of Tokyo. In this study, patients were enrolled from all over Japan, which may account for differences ${ }^{29)}$.

In addition, the percentage of patients with $\mathrm{FH}$ according to the JAS guidelines reported by Ohmura et al. was $5.7 \%{ }^{29)}$, whereas in this study $1.9 \%$ of patients would be diagnosed with $\mathrm{FH}$ using the JAS 2017 guidelines (without additional genetic testing) and $7.7 \%$ would be diagnosed with FH when the JAS guidelines were supplemented with genetic testing ${ }^{29)}$. FH status was determined using the JAS 2017 guidelines with and without additional genetic testing. When genetic testing was incorporated with the JAS 2017 guidelines, the proportion of patients identified as having $\mathrm{FH}$ was similar to those diagnosed with definite FH by the Dutch Lipid Clinical Network and Simon Broome guidelines $(3.9 \%$ and $7.2 \%$, respectively). This suggests that the JAS guidelines without genetic testing might be insufficient for diagnosis of $\mathrm{FH}$ in patients with ACS in Japan. In addition, the cut-off point of LDL-C and ATT was analyzed using ROC curves of parameters. According to these ROC curves, we propose that cut-off values of LDL-C $165 \mathrm{mg} / \mathrm{dL}$ and ATT $8.0 \mathrm{~mm}$ could lead to more accurate diagnosis of $\mathrm{FH}$ if incorporated into the current JAS guidelines.

Because of variability in LDL-C after ACS, availability of genetic testing in patients with suspected $\mathrm{FH}$ is important in this population. Currently, there are a limited number of hospitals in Japan that can conduct genetic testing for $\mathrm{FH}$, and genetic testing for $\mathrm{FH}$ is not reimbursed by health insurance providers ${ }^{6}$. Stigma of genetic disease (e.g., social perceptions and fears of insurance denial) and lack of resources (such as accessibility to geneticists and genetic counseling) may also hinder diagnosis of $\mathrm{FH}^{30}, 31$. These barriers need to be removed to improve the diagnostic rate of $\mathrm{FH}$ and allow cascade screening, which will lead to appropriate lipidlowering therapy with high-dose statins, ezetimibe, and PCSK9 inhibitors for these patients, lowering their risk of premature cardiovascular events. However, although genetic testing will improve diagnosis in this population, many patients with $\mathrm{FH}$ will not have an identifiable mutation. Therefore, clinical evaluation of those presenting with ACS remains crucial.

Interestingly, although a direct comparison may not be meaningful because of the small sample size, a lower proportion of patients with pathogenic variants had a family history of CAD than had those without pathogenic variants $(4.0 \%$ vs. $6.9 \%)$. This may be due to underreporting or the fact that patients with pathogenic variants (and their families) have severe enough hypercholesterolemia that they are already treated with statins, thereby reducing CAD.

This study is limited by the nature of the observational study design. In this analysis, untreated LDL-C levels were only available for three of the patients with pathogenic variants. Ohmura et al. also highlighted the difficulties of collecting LDL-C values for use in the diagnosis of $\mathrm{FH}$ and that collection of blood samples varied among the facilities included in their study ${ }^{29)}$. Furthermore, information on family 
history was unknown for 77 (17.9\%) patients overall and seven $(28.0 \%)$ patients with pathogenic variants. In addition, not all patients received genetic testing, and available data for each criterion in the JAS, Dutch Lipid Clinical Network, and Simon Broome guidelines were not complete for all patients. Furthermore, although $A P O B$ mutations are generally not found in the Japanese population, and so were not included in the genetic testing used here, sporadic mutations may occur. In fact, subsequent to this analysis, the first case of $\mathrm{FH}$ due to a known pathogenic $A P O B$ gene variant was reported in a Japanese family ${ }^{32)}$. Although this study has only examined variants of the $L D L R$ and PCSK9 genes, it might be more informative for $\mathrm{FH}$ diagnosis if polygenic variants are examined, such as $A P O E 4$ and the sporadic mutations of $A P O B$. Finally, the generalizability of these findings is limited to the Japanese population.

\section{Conclusion}

These results revealed genetic mutations of $\mathrm{FH}$ found among Japanese patients with ACS. However, to increase the diagnostic accuracy of patients presenting with ACS, the diagnostic thresholds used in the JAS guidelines may need to be re-evaluated for these patients. These findings highlight the importance of genetic testing and family history in the diagnosis of FH in patients with ACS, as well as screening and diagnosis of $\mathrm{FH}$ before the initiation of statins in patients that may have FH. A substantial number of high-risk patients could benefit from genetic testing. In addition, we propose that cut-off values of LDL-C $165 \mathrm{mg} / \mathrm{dL}$ and ATT $8.0 \mathrm{~mm}$ could improve diagnosis of $\mathrm{FH}$ if incorporated into the current JAS guidelines.

\section{Acknowledgements}

The authors thank the patients, their families, and all investigators involved in the study: Tamio Teramoto of Teikyo University (Tokyo, Japan), Shun Ishibashi of Jichi Medical University (Tochigi, Japan), Kotaro Yokote of Chiba University (Chiba, Japan), Tomonori Okamura of Keio University (Tokyo, Japan), and Hiroyuki Daida of Juntendo University (Tokyo, Japan) for collaboration and advice regarding planning of the study; Mebix (Tokyo, Japan) for assistance with study implementation/operation; BML (Tokyo, Japan) for PCSK9-related and genome-related analysis; CTD (Tokyo, Japan) for consulting; and Shizuya Yamashita of Rinku General Medical Center (Osaka, Japan) and Toru Yoshizumi of Kawasaki Hospital (Hyogo, Japan). The authors would also like to thank Yoshiharu Takagi and Yukiko Morimoto of Sanofi for providing support with statistical analysis; and Yasunori Nakahigashi and Makiko Usami of Sanofi for assistance with study implementation/ operation. Medical writing assistance and editorial support, under the direction of the authors, were provided by Kate Carolan, $\mathrm{PhD}$, of Prime Global (Knutsford, United Kingdom) according to Good Publication Practice guidelines (Link) and funded by Sanofi. The authors were involved in the study design as well as the collection, analysis, and interpretation of data. All authors had full access to all the data in this study and take complete responsibility for the integrity of the data and accuracy of the data analysis.

\section{Financial Support}

This study was funded by Sanofi and Regeneron Pharmaceuticals, Inc.

\section{Conflicts of Interest}

Mariko Harada-Shiba has received honoraria from Amgen, Astellas, and Sanofi; and research grants from Aegerion, Kaneka and Recordati and held stock of Liid Pharma. Junya Ako has received honoraria from Amgen and Sanofi. Atsushi Hirayama has received honoraria and research grants from Sanofi. Masato Nakamura has received honoraria from Astellas, Amgen, and Sanofi; and research grants from Sanofi. Atsushi Nohara has received honoraria from Sanofi. Kayoko Sato has received research grants from Astellas, Takeda, and Aegerion. Yoshitaka Murakami does not have any conflicts of interest to declare. Ryusuke Koshida was an employee of Sanofi K.K at the time of this study. Asuka Ozaki is an employee of Sanofi K.K. Hidenori Arai has received lecture fees from Daiichi Sankyo, Kowa, MSD, Pfizer, and Sanofi.

\section{References}

1) Bouhairie VE and Goldberg AC: Familial hypercholesterolemia. Cardiology clinics, 2015; 33: 169-179

2) Defesche JC, Gidding SS, Harada-Shiba M, Hegele RA, Santos RD and Wierzbicki AS: Familial hypercholesterolaemia. Nat Rev Dis Primers, 2017; 3: 17093

3) Harada T, Inagaki-Tanimura K, Nagao M, Sato Y, Sudo M, Okajima F, Sugihara H and Oikawa S: Frequency of Achilles Tendon Xanthoma in Patients with Acute Coronary Syndrome. J Atheroscler Thromb, 2017; 24: 949-953

4) Teramoto T, Sasaki J, Ishibashi S, Birou S, Daida H, Dohi $S$, Egusa G, Hiro $T$, Hirobe $K$, Iida $M$, Kihara $S$, Kinoshita M, Maruyama C, Ohta T, Okamura T, Yamashita S, Yokode M, Yokote K, Harada-Shiba M, Arai 
H, Bujo H, Nohara A, Ohta T, Oikawa S, Okada T and Wakatsuki A: Familial hypercholesterolemia. J Atheroscler Thromb, 2014; 21: 6-10

5) Nordestgaard BG, Chapman MJ, Humphries SE, Ginsberg HN, Masana L, Descamps OS, Wiklund O, Hegele RA, Raal FJ, Defesche JC, Wiegman A, Santos RD, Watts GF, Parhofer KG, Hovingh GK, Kovanen PT, Boileau C, Averna M, Boren J, Bruckert E, Catapano AL, Kuivenhoven JA, Pajukanta P, Ray K, Stalenhoef AF, Stroes E, Taskinen MR, Tybjaerg-Hansen A and European Atherosclerosis Society Consensus Panel: Familial hypercholesterolaemia is underdiagnosed and undertreated in the general population: guidance for clinicians to prevent coronary heart disease: consensus statement of the European Atherosclerosis Society. Eur Heart J, 2013; 34: 3478-3490a

6) Harada-Shiba M, Arai H, Ishigaki Y, Ishibashi $S$, Okamura T, Ogura M, Dobashi K, Nohara A, Bujo H, Miyauchi K, Yamashita S and Yokote K: Guidelines for Diagnosis and Treatment of Familial Hypercholesterolemia 2017. J Atheroscler Thromb, 2018; 25: 751-770

7) Simon Broome Register Group: Risk of fatal coronary heart disease in familial hypercholesterolaemia. Scientific Steering Committee on behalf of the Simon Broome Register Group. BMJ, 1991; 303: 893-896

8) Hovingh GK, Davidson MH, Kastelein JJ and O'Connor AM: Diagnosis and treatment of familial hypercholesterolaemia. Eur Heart J, 2013; 34: 962-971

9) Hartgers ML, Ray KK and Hovingh GK: New approaches in detection and treatment of familial hypercholesterolemia. Curr Cardiol Rep, 2015; 17: 109

10) Hori $M$, Ohta $N$, Takahashi $A$, Masuda $H$, Isoda $R$, Yamamoto S, Son C, Ogura M, Hosoda K, Miyamoto Y and Harada-Shiba M: Impact of LDLR and PCSK9 pathogenic variants in Japanese heterozygous familial hypercholesterolemia patients. Atherosclerosis, 2019; 289: 101-108

11) Harada-Shiba M, Takagi A, Miyamoto $Y$, Tsushima $M$, Ikeda Y, Yokoyama $S$ and Yamamoto A: Clinical features and genetic analysis of autosomal recessive hypercholesterolemia. J Clin Endocrinol Metab, 2003; 88: 2541-2547

12) Nordestgaard BG and Benn M: Genetic testing for familial hypercholesterolaemia is essential in individuals with high LDL cholesterol: who does it in the world? Eur Heart J, 2017; 38: 1580-1583

13) Watts GF, Gidding S, Wierzbicki AS, Toth PP, Alonso R, Brown WV, Bruckert E, Defesche J, Lin KK, Livingston M, Mata P, Parhofer KG, Raal FJ, Santos RD, Sijbrands EJ, Simpson WG, Sullivan DR, Susekov AV, Tomlinson B, Wiegman A, Yamashita S, Kastelein JJ and International Familial Hypercholesterolemia Foundation: Integrated guidance on the care of familial hypercholesterolaemia from the International FH Foundation. Eur J Prev Cardiol, 2015; 22: 849-854

14) Nakamura M, Uno K, Hirayama A, Ako J, Nohara A, Arai $\mathrm{H}$ and Harada-Shiba M: Exploration into lipid management and persistent risk in patients hospitalised for acute coronary syndrome in Japan (EXPLORE-J): protocol for a prospective observational study. BMJ Open, 2017; 7: e014427

15) Amsterdam EA, Wenger NK, Brindis RG, Casey DE, Jr.,
Ganiats TG, Holmes DR, Jr., Jaffe AS, Jneid H, Kelly RF, Kontos MC, Levine GN, Liebson PR, Mukherjee D, Peterson ED, Sabatine MS, Smalling RW and Zieman SJ: 2014 AHA/ACC Guideline for the Management of Patients with Non-ST-Elevation Acute Coronary Syndromes: a report of the American College of Cardiology/ American Heart Association Task Force on Practice Guidelines. J Am Coll Cardiol, 2014; 64: e139-e228

16) Nanchen D, Gencer B, Auer R, Räber L, Stefanini GG, Klingenberg R, Schmied CM, Cornuz J, Muller O, Vogt P, Jüni P, Matter CM, Windecker S, Lüscher TF, Mach F and Rodondi N: Prevalence and management of familial hypercholesterolaemia in patients with acute coronary syndromes. Eur Heart J, 2015; 36: 2438-2445

17) Amor-Salamanca A, Castillo S, Gonzalez-Vioque E, Dominguez F, Quintana L, Lluís-Ganella C, Escudier JM, Ortega J, Lara-Pezzi E, Alonso-Pulpon L and Garcia-Pavia P: Genetically Confirmed Familial Hypercholesterolemia in Patients With Acute Coronary Syndrome. J Am Coll Cardiol, 2017; 70: 1732-1740

18) Harada-Shiba M, Ako J, Arai H, Hirayama A, Murakami Y, Nohara A, Ozaki A, Uno K and Nakamura M: Prevalence of familial hypercholesterolemia in patients with acute coronary syndrome in Japan: Results of the EXPLORE-J study. Atherosclerosis, 2018; 277: 362-368

19) Nakamura M, Ako J, Arai H, Hirayama A, Murakami Y, Nohara A, Uno K, Ozaki A and Harada-Shiba M: Investigation into lipid management in acute coronary syndrome patients from the EXPLORE-J study. J Atheroscler Thromb, 2019; 26: 559-572

20) Youden WJ: Index for rating diagnostic tests. Cancer, 1950; 3: 32-35

21) $\mathrm{Yu}$ W, Nohara A, Higashikata $T, \mathrm{Lu} H$, Inazu $A$ and Mabuchi H: Molecular genetic analysis of familial hypercholesterolemia: spectrum and regional difference of LDL receptor gene mutations in Japanese population. Atherosclerosis, 2002; 165: 335-342

22) Noguchi T, Katsuda S, Kawashiri MA, Tada H, Nohara A, Inazu A, Yamagishi M, Kobayashi J and Mabuchi $\mathrm{H}$ : The E32K variant of PCSK9 exacerbates the phenotype of familial hypercholesterolaemia by increasing PCSK9 function and concentration in the circulation. Atherosclerosis, 2010; 210: 166-172

23) Han SM, Hwang B, Park T-G, Kim D-I, Rhee M-Y, Lee B-K, Ahn YK, Cho BR, Woo J and Hur S-H: Genetic testing of Korean familial hypercholesterolemia using whole-exome sequencing. PloS One, 2015; 10: e0126706

24) Marduel M, Carrié A, Sassolas A, Devillers M, Carreau V, Di Filippo M, Erlich D, Abifadel M, Marques - Pinheiro A and Munnich A: Molecular spectrum of autosomal dominant hypercholesterolemia in France. Human Mutation, 2010; 31: E1811-E1824

25) Mabuchi H, Nohara A, Noguchi T, Kobayashi J, Kawashiri MA, Inoue T, Mori M, Tada H, Nakanishi C, Yagi K, Yamagishi M, Ueda K, Takegoshi T, Miyamoto S, Inazu $\mathrm{A}$ and Koizumi J: Genotypic and phenotypic features in homozygous familial hypercholesterolemia caused by proprotein convertase subtilisin/kexin type 9 (PCSK9) gain-of-function mutation. Atherosclerosis, 2014; 236: 54-61

26) Rosenson RS: Myocardial injury: the acute phase response 
and lipoprotein metabolism. Journal of the American College of Cardiology, 1993; 22: 933-940

27) Harada-Shiba M, Arai H, Okamura T, Yokote K, Oikawa S, Nohara A, Okada T, Ohta T, Bujo H, Watanabe M, Wakatsuki A and Yamashita S: Multicenter study to determine the diagnosis criteria of heterozygous familial hypercholesterolemia in Japan. J Atheroscler Thromb, 2012; 19: 1019-1026

28) Tsouli SG, Xydis V, Argyropoulou MI, Tselepis AD, Elisaf $\mathrm{M}$ and Kiortsis DN: Regression of Achilles tendon thickness after statin treatment in patients with familial hypercholesterolemia: an ultrasonographic study. Atherosclerosis, 2009; 205: 151-155

29) Ohmura H, Fukushima Y, Mizuno A, Niwa K, Kobayashi Y, Ebina T, Kimura K, Ishibashi $S$ and Daida $H$ : Estimated Prevalence of Heterozygous Familial
Hypercholesterolemia in Patients With Acute Coronary Syndrome. Int Heart J, 2017; 58: 88-94

30) New York-Mid-Atlantic Consortium for Genetic Newborn Screening Services: Understanding genetics: a New York, mid-Atlantic guide for patients and health professionals, Lulu.com, 2009

31) Delikurt T, Williamson GR, Anastasiadou V and Skirton $\mathrm{H}$ : A systematic review of factors that act as barriers to patient referral to genetic services. Eur J Hum Genet, 2015; 23: 739-745

32) Hori M, Takahashi A, Son C, Ogura M and HaradaShiba M: The first Japanese cases of familial hypercholesterolemia due to a known pathogenic APOB gene variant, c.10580 G>A: p.(Arg3527Gln). Journal of Clinical Lipidology, 2020; 14: 482-486 
Supplementary Table 1 . Characteristics of patients with pathogenic variants $(n=25)$

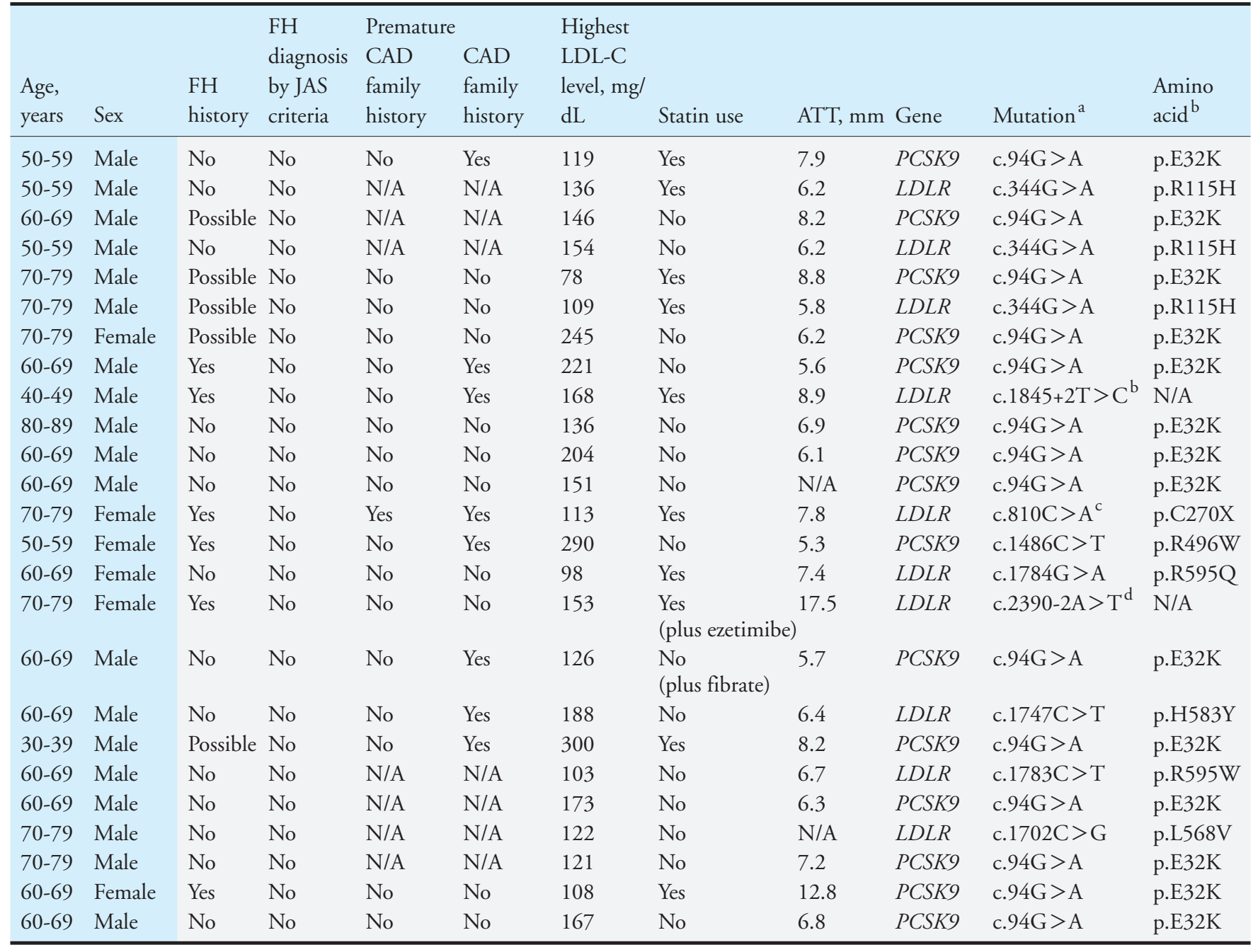

ATT, Achilles tendon thickness; CAD, coronary artery disease; FH, familial hypercholesterolemia; JAS, Japanese Atherosclerosis Society; LDL-C, low-density lipoprotein cholesterol; N/A, not available.

${ }^{a}$ Mutations were missense mutations, except for splice donor variant, stop codon mutation, and splice acceptor variant (denoted by ${ }^{\mathrm{b}}$, ${ }^{\mathrm{c}}$, and ${ }^{\mathrm{d}}$, respectively).

${ }^{b}$ Amino acid abbreviations: C, cysteine; E, glutamic acid; H, histidine; K, lysine; L, leucine; Q, glutamine; R, arginine; V, valine; W, tryptophan; X, stop codon; Y, tyrosine. 
Supplementary Table 2. Characteristics of patients with indeterminate variants $(n=10)$

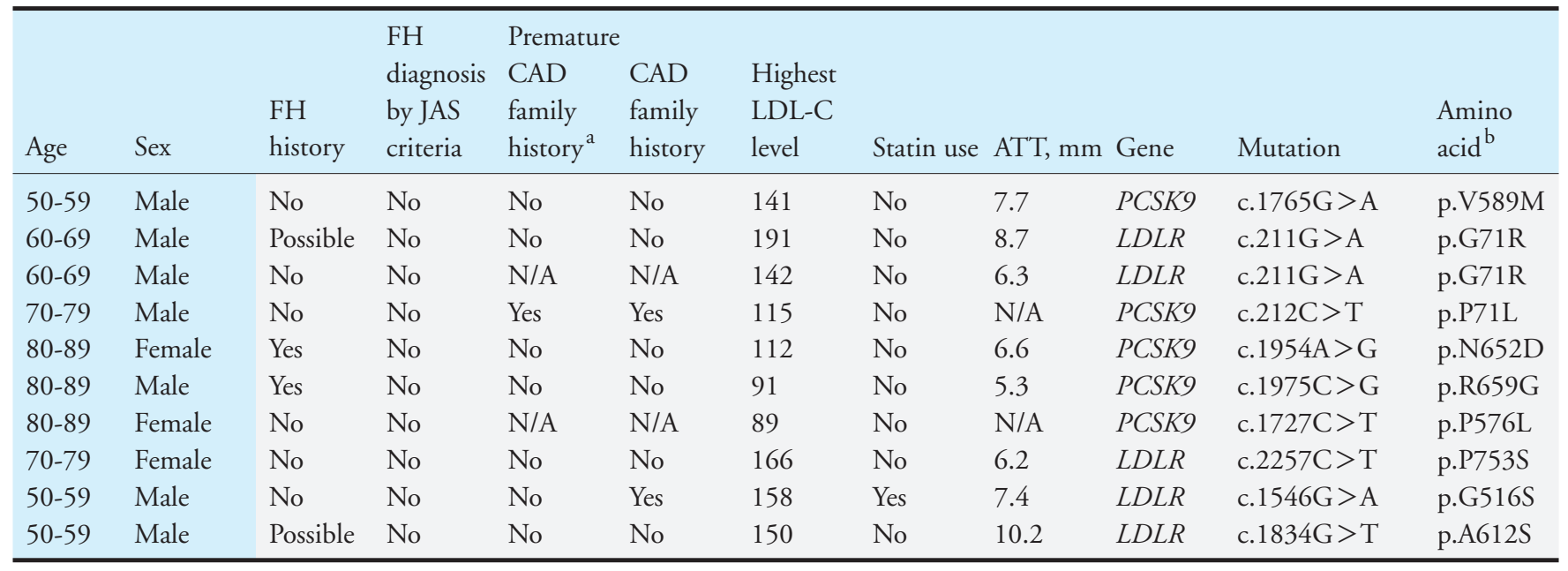

ATT, Achilles tendon thickness; CAD, coronary artery disease; FH, familial hypercholesterolemia; JAS, Japanese Atherosclerosis Society; LDL-C, low-density lipoprotein cholesterol; N/A, not available.

${ }^{a}$ Male $<55$ years, female $<65$ years.

${ }^{\mathrm{b}}$ Amino acid abbreviations: A, alanine; D, aspartic acid; G glycine; L, leucine; M, methionine; N, asparagine; P, proline; R, arginine; S, serine; V, valine.

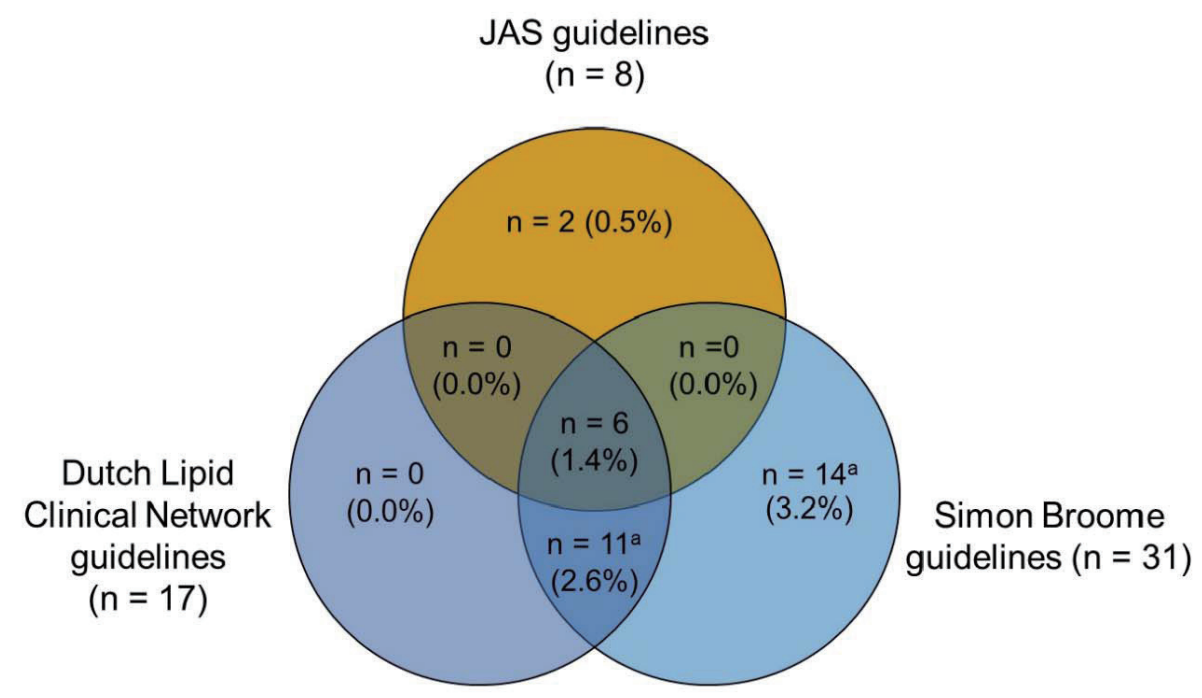

Supplementary Fig. 1. Diagnosis of patients with FH based on the clinical criteria of JAS, Dutch Lipid Clinical Network, and Simon Broome guidelines

FH, familial hypercholesterolemia; JAS, Japan Atherosclerosis Society.

In total, 398 patients did not meet any of the three diagnostic guidelines.

${ }^{\mathrm{a}}$ All patients carry any pathogenic variants for $\mathrm{FH}$ (definite $\mathrm{FH}$ ). 